www.jmscr.igmpublication.org

Impact Factor 5.84

Index Copernicus Value: 71.58

ISSN (e)-2347-176x ISSN (p) 2455-0450

crossref DOI: _https://dx.doi.org/10.18535/jmscr/v5i9.82

Journal Of Medical Science And Clinical Research

\title{
Seroprevalence of Toxoplasma Gondii among Pregnant Women Having Bad Obstetric History in a Tertiary Care Hospital of Eastern Odisha
}

\author{
Authors \\ J.Majhi $^{1}$, R.K. Panda ${ }^{2}$, M. Das ${ }^{3}$, N.Chayani ${ }^{4}$ \\ ${ }^{1}$ Post Graduate Trainee, ${ }^{2}$ Assistant Professor, ${ }^{3}$ Associate Professor, ${ }^{4}$ Professor \& Head, Microbiology, \\ S.C.B Medical College, Cuttack \\ Corresponding Author \\ Dr Rakesh Kumar Panda \\ Assistant Professor, Department of Microbiology, S.C.B Medical College, Cuttack, Odisha, India \\ Contact Number: 9437310147, Email: drrakesh_76@rediffmail.com
}

\begin{abstract}
Introduction: Toxoplasma gondii infection is a major risk factor in women having bad obstetric history. If vertically transmitted it can result in adverse pregnancy out comes ranging from abortion to congenital anomalies.

Objective: The current case control study is undertaken to evaluate the prevalence of T.gondii and the associated environmental and personal factors that may contribute to infection, among pregnant women in the eastern part of Odisha.

Materials and Methods: Serum samples of 120 pregnant women having bad obstetric history and 60 pregnant women without such history of age group 20 to $\geq 40$ years attending a tertiary care Hospital in Cuttack district of Odisha were tested for anti-Toxoplasma IgG and IgM antibodies by ELISA. Epidemiological data of the women was collected through a standard questionnaire.

Results: The prevalence of anti-Toxoplasma IgG was $17.5 \%$ in cases and $13.3 \%$ in controls, and of IgM was $2.5 \%$ in cases and 1.7\% in controls. Sero prevalence increased steadily from 20-24 yrs (13\%) to 30-34 yrs (30\%) and most women were in second trimester. Though statistically significant association was observed between $T$. Gondii seroprevalence and women of low socio economic status living in urban areas, no such association was observed with other risk factors like contact with cat and soil or consumption of meat, raw salad and contaminated water.

Conclusion: As Toxoplasma seroprevalence among poor urban women is considerable and support the concern that women may be vulnerable to such infection all pregnant women should be screened routinely and be provided preconception health education regarding Toxoplasmosis to prevent primary infection.

Keywords: Toxoplasma gondii, bad obstetric history, seropositivity, ELISA
\end{abstract}

\section{Introduction}

Toxoplasma gondii is an obligatory intracellular protozoan parasite. Cats and wild Felines are the only definitive host while other worm blooded animals including humans are intermediate hosts $^{[1]}$. Infection is acquired by ingestion of viable tissue cysts in uncooked or under cooked meat or oocysts excreted by cats that contaminate food and water or by vertical transmission ${ }^{[2]}$. It was estimated that one third of the world's population is infected by T.gondii ${ }^{[3]}$.Studies show that about $90 \%$ of infections in immune competent humans are asymptomatic.

While up to $10 \%$ present with fever, malaise, head ache with cervical lymphadenopathy or ocular disease $^{[4]}$. In immune suppressed patients, toxopl- 
asmosis can cause severe encephalitis by acute infection or reactivation of latent infection ${ }^{[5]}$. Infection during pregnancy may cause spontaneous abortion, still birth, or congenital anomalies such as microcephaly, hydrocephaly, intrauterine growth retardation, chorioretinitis in the offspring depending on the gestational age, when maternal infection is acquired. It may present late in childhood as deafness, blindness and mental retardation ${ }^{[6]}$. Congenital infections acquired during the first trimester are more severe than those acquired in the second and third trimester $^{[7]}$. Anti-parasitic treatment during pregnancy may reduce the risk of transmission to the foetus if it is diagnosed early ${ }^{[8]}$. For diagnosis, isolation of T. gondii or demonstration of DNA by PCR are confirmative methods but, these are practically difficult ${ }^{[9]}$. Hence, Toxoplasmosis is mostly diagnosed by detection of specific antibodies by Latex agglutination test, indirect fluorescent antibody test or the specific $\operatorname{IgM}$ and IgG-based ELISA ${ }^{[10]}$. Following an acute infection IgM antibody titres rise from 5 days to weeks, reaching a peak after 1 to 2 months then rapidly decline. But, in many cases IgM antibody may persist for years ${ }^{[11]}$. IgG antibodies appear later than IgM, detectable within 1 to 2 weeks and reach the peak after 3 to 6 months following acute infection. They will be detectable for years, even throughout life after acquiring infection ${ }^{[12]}$. If IgG is positive and $\operatorname{IgM}$ is negative, this indicates an old infection. If both IgG and IgM are positive, this indicates possibility of a recent infection acquired within a year or a false-positive test result. If $\operatorname{IgG}$ and $\operatorname{IgM}$ are both negative, this indicates the absence of infection or extremely recent acute infection. ${ }^{[12][13]}$ If acute infection is suspected, repeat testing is recommended within 2 to 3 weeks in which,4-fold rise in IgG antibody

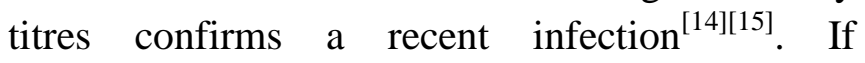
interpretation of $\mathrm{IgG}$ and $\mathrm{IgM}$ titers are difficult to establish acute infection, IgG avidity test should be done. High avidity implies that infection occurred at least 5 months before testing ${ }^{[12]}$.
Since anti-toxoplasma antibody testing is not routinely done in many parts of country, information regarding infection, diagnosis and interpretation of test results is lacking. As there was limited data on seroprevalence of Toxoplasmosis in pregnant women in eastern Odisha, the present study was carried out to evaluate the disease prevalence, and its association with known risk factors.

\section{Materials and Methods}

\section{Study design, area and population}

This prospective case control study was conducted from September 2014 to October 2016 in a tertiary care Government Hospital at Cuttack District of Odisha.

Cuttack a part of eastern India has a tropical wet, monsoon rainforest type climate. Average rain fall is $1700 \mathrm{~mm}$, humidity of $78 \%$ and average annual temperature is $27.5^{\circ} \mathrm{C}$. Coordinates of the district are, Latitude $20^{\circ} 30^{\prime} 0^{\prime \prime} \mathrm{N}$ and longitude $85^{\circ} 50^{\prime} 0^{\prime \prime}$ E.

180 pregnant women above 19 years of age having gestation within 28 weeks, who attended the Antenatal and Gynaecology Unit of our Hospital were included in the study. The $\mathrm{BOH}$ (bad obstetric group) group consisted of 120 women with a history of abortion, IUD or still birth, IUGR; preterm delivery or congenital anomalies and control group consisted of 60 women without history of any adverse pregnancy out come. Women with other medical conditions which could cause miscarriage such as hypertension, diabetes mellitus, syphilis, rhesus incompatibility, and consanguinity were excluded from the study. Similarly women, having AIDS or severe autoimmune disorder e.g Rhumatoid arthritis, or receiving cancer chemotherapy and other forms of immunosuppressive therapy, were excluded from study.

Informed written consent was obtained from all the participants. Ethical clearance for the study was obtained from the institutional Ethics Review Committee. 
Data collection: Epidemiological data of the participants such as age, residence type, socioeconomic status, period of gestation, obstetric history as well as inforation regarding association with known risk factors for infection such as contact with cats or soil, consumption of raw salads, undercooked meat or contaminated water and past history of blood transfusions or organ transplantation were collected using an interviewer-administered questionnaire.

Laboratory detection of anti Toxo IgG and IgM antibodies

Two millilitres of venous blood was collected aseptically from each participant. Serum was separated by centrifugation at $3000 \mathrm{rpm}$ for 10 minutes, labelled and stored at $-20^{\circ} \mathrm{C}$ until tested. All the sera were tested for the presence of Toxoplasma gondii specific antibodies IgM and IgG using ELISA kit of Delta Biologicals (Subsidiary of ERBA Diagnostics-ITALY) according to the manufacturer's guidelines. The results were read by a Micro well reader and compared in parallel with positive and negative controls. Optical density was read at $450 \mathrm{~nm}$ on an ELISA reader. Cut-off points and antibody index calculations were done according to manufacturer's instructions. When the absorbance of the sample was higher than that of cut-off, the sample was considered positive for the presence of specific IgM/ IgG .The ratio between the OD value of the sample and that of the cut-off was calculated. The sample was considered positive, if the ratio is $>1.2$, negative if the ratio is $<0.8$ and border line positive, if the ratio is $\pm 20 \%$ of cut-off (0.8-1.2).

\section{Statistical Analysis}

Data was entered in excel sheet and imported into software Statistical Package for the Social Sciences (SPSS version 21) for analysis. Binomial data were evaluated by chi-square to test statistically significant differences. The odd ratio (OR) and its 95\% confidence interval (CI) were used to estimate the strength of the association between the $T$. gondii infection and the associated risk factors. Incidences (IgM positivity) and prevalence (IgG positivity) rates are expressed as percentages. P-values less than 0.05 were considered statistically significant.

\section{Results}

Serum of total 180 pregnant women attending Antenatal and Gynaecology Unit of the Hospital, were screened for anti Toxoplasma IgG and IgM antibodies by ELISA.

Over all Toxoplasma seropositivity among pregnant women in this study was $16.7 \%$ (30/180). Seropositivity was higher in women with bad obstetric history (BOH), (22/120:18.3\%) than the control groups $(08 / 60: 13.3 \%)$. In the $\mathrm{BOH}$ group 21(17.5\%) women were positive for Toxo-IgG and $3(2.5 \%)$ women for Toxo-IgM antibody. Among those three $\operatorname{IgM}$ positive women, two were also positive for $\mathrm{IgG}$, and one was negative for IgG. Similarly in the control group 8 women were positive for Toxo$\operatorname{IgG}(13.3 \%)$ and one woman for $\operatorname{Toxo}-\operatorname{IgM}(1.7 \%)$ who was also, positive for IgG. IgM seroprevalance rate among $\operatorname{IgG}$ positives is $9.5 \%(2 / 21)$ in $\mathrm{BOH}$ groups which, indicates incidence of recent Toxoplasma infection (Table-1).In the $\mathrm{BOH}$ group maximum seroprevalance $(30 \%)$ was observed in women between 30 to $34 \mathrm{yrs}$ but, maximum participants were in age group between 25 to 29 yrs, who had seroprevalance of $18.9 \%$.In the control group, women between 30 to $34 \mathrm{yrs}$, also had maximum seroprevalance (14.3\%) (Table-2). In the $\mathrm{BOH}$ group highest seroprevalance was also observed in $2^{\text {nd }}$ Trimester $(22 \%)$, followed by $1^{\text {st }}$ Trimester $(18.75 \%)$ and $3^{\text {rd }}$ Trimester $(9 \%)$. Pre term delivery and abortion (67/120:55.8\%) were most common bad obstetric history, but Toxoplasma seroprevalance was highest in women with history of abortion (33.3\%) followed by IUD $(16 \%)$ and preterm delivery $(14.7 \%)$ (Table$3 \& 4)$.In $\mathrm{BOH}$ group, Seroprevalance were more, in urban areas (13/61:21.3\%) than rural areas (9/59:15.25\%). Again in urban areas, women of low socioeconomic status had more seroprevalance, $(45.8 \%)$ than their rural counterparts (21.7\%) (Table-5). 
Table-1: Seropositivity of Toxoplasma-IgG and IgM in different ages among BOH and control groups

\begin{tabular}{|l|c|c|c|c|c|c|c|}
\hline Type of groups & $\begin{array}{c}\text { No of } \\
\text { sera } \\
\text { Only IgG +ve(\%) }\end{array}$ & $\begin{array}{c}\text { No of sera } \\
\text { Only IgM } \\
\text { +ve(\%) }\end{array}$ & $\begin{array}{c}\text { No of sera both } \\
\text { Ig M \& Ig G + } \\
\text { ve(\%) }\end{array}$ & $\begin{array}{c}\text { Total No of sero- } \\
\text { positives(\%) }\end{array}$ & $\begin{array}{c}\text { Total no of sero- } \\
\text { negatives(\%) }\end{array}$ & Total & P- value \\
\hline BOH group & $19(15.8)$ & $1(0.8)$ & $2(1.7)$ & $22(18.3)$ & $98(81.7)$ & $120(100 \%)$ & 0.396 \\
\hline Control group & $7(11.7)$ & 0 & $1(1.7)$ & $08(13.3)$ & $52(8.7)$ & $60(100 \%)$ & 0.396 \\
\hline
\end{tabular}

Table-2 : Sero positivity of Toxoplasma-IgG and IgM in different ages among BOH and control groups

\begin{tabular}{|c|c|c|c|c|c|c|}
\hline Age group & $\begin{array}{c}\text { no of cases } \\
\text { (BOH group) }\end{array}$ & Sero positivity & P-value & $\begin{array}{c}\text { no of cases } \\
\text { (Control group) }\end{array}$ & Sero positivity & $\mathrm{P}$-value \\
\hline $20-24$ & 23 & $3(13 \%)$ & \multirow[b]{6}{*}{0.311} & 10 & $2(20 \%)$ & \multirow[b]{6}{*}{0.831} \\
\hline $25-29$ & 37 & $7(18.9 \%)$ & & 29 & $4(13.8 \%)$ & \\
\hline $30-34$ & 30 & $9(30 \%)$ & & 14 & $2(14.3 \%)$ & \\
\hline $35-39$ & 27 & $3(11.1 \%)$ & & 06 & $0(00 \%)$ & \\
\hline$\geq 40$ & 3 & 0 & & 01 & $0(00 \%)$ & \\
\hline Total & 120 & $22(18.3 \%)$ & & 60 & $08(13.3 \%)$ & \\
\hline
\end{tabular}

Table-3 : Seropositivity of Toxoplasma IgG and IgM in different trimesters among BOH groups.

\begin{tabular}{|l|c|c|}
\hline Age group & No of cases & Sero-positivity(\%) \\
\hline $1^{\text {st }}$ Trimester & 48 & $9(18.75 \%)$ \\
\hline $2^{\text {nd }}$ Trimester & 50 & $11(22 \%)$ \\
\hline $3^{\text {rd }}$ Trimester & 22 & $2(9 \%)$ \\
\hline Total & 120 & $22(18.3 \%)$ \\
\hline
\end{tabular}

Table-4: Association of bad obstetrical events with Seropositivity among BOH groups.

\begin{tabular}{|l|c|c|c|c|}
\hline Type of BOH & No of Cases & No of Seropositives (\%) & No of Seronegatives (\%) & P-value \\
\hline Abortion & 33 & $11(33.3 \%)$ & $22(66.7 \%)$ & $21(84 \%)$ \\
\cline { 1 - 3 } IUD/StillBirth & 25 & $4(16 \%)$ & $29(85 \%)$ \\
\cline { 1 - 4 } Pre term delivery & 34 & $5(14.7 \%)$ & $18(94.7 \%)$ \\
\hline IUGR & 19 & $1(5.3 \%)$ & $8(88.9 \%)$ \\
\hline Congenital anomalis & 9 & $1(11.1 \%)$ & $98(81.7 \%)$ \\
\cline { 1 - 3 } Total & $120(100 \%)$ & $22(18.3 \%)$ & \\
\end{tabular}

Table 5 : Association of various risk factors with Toxoplasma Seropositivity among BOH and control group

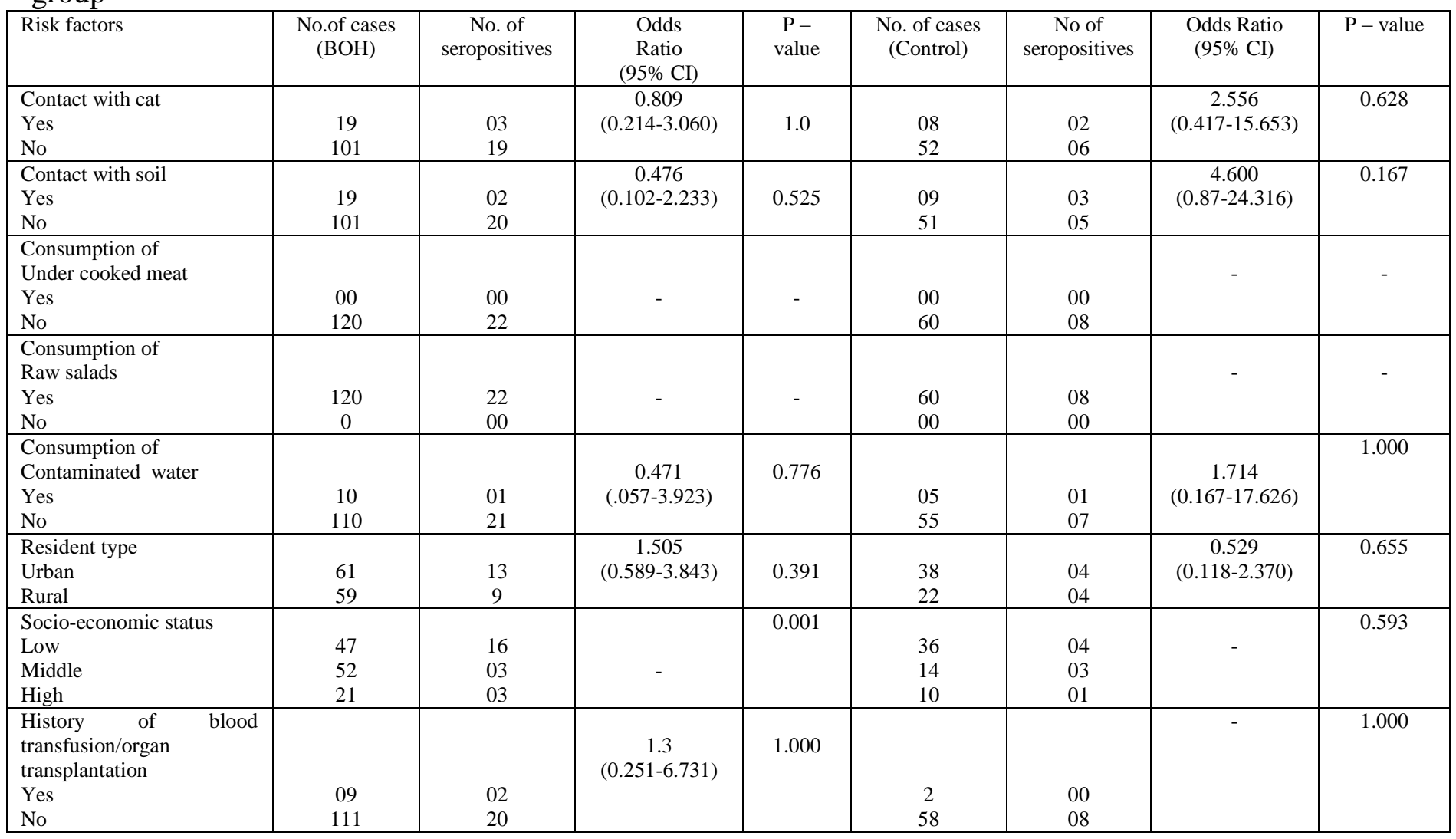




\section{Discussion}

Various epidemiological studies show that prevalence of $T$. gondii infection in pregnant women varies substantially among countries. In European countries, prevalence varies from 9 to $67 \%^{[16]}$.In Asian countries, low prevalence were found in Korea(0.8\%) and Vietnam(11.2\%) but, high prevalence were found in Nepalese , and Indian populations ${ }^{[17][18][19][20]}$. As reported previously seroprevalence of toxoplasmosis in Indian pregnant women varies between $5 \%$ and $80 \% .^{[20][21]}$ Over all Toxoplasma seropositivity in this study was $16.7 \%(30 / 180)$ among pregnant women viz was less than the average pan India Toxoplasma-sero prevalence $(22.4 \%)$, where Singh et.al(2013) observed $\operatorname{IgG}$ prevalence of $37.3 \%$ in South India, 21.2\% in East India , 19.7\% in North India and $8.8 \%$ in West India and of IgM ranged from $0.4 \%$ to $2.9 \%$ in four study zones $^{[22]}$.In our study the sero prevalence of $T$. gondii infection in the $\mathrm{BOH}$ group was $18.3 \%$ vs $13.3 \%$ in the control group which was similar to prevalence rate of $20 \%$ in spontaneous abortion verses $5 \%$ in control, as observed by Anubhuti et.al ${ }^{[23]}$. In this study all the IgM positive sera were $\operatorname{IgG}$ positive, except one in $\mathrm{BOH}$ group which was IgG negative. This woman could have acquired very recent Toxoplasma infection where Ig $\mathrm{G}$ titer has not yet risen. In the current study among the $\mathrm{BOH}$ group, $0.8 \%$ were seropositive for only $\operatorname{IgM}$ antibodies which indicates acute infection, $15.8 \%$ were seropositive for only $\operatorname{IgG}$ antibodies which indicate chronic infection, and $1.7 \%$ were seropositive for both $\operatorname{IgM}$ and $\operatorname{IgG}$ antibodies which indicates possible recent past infection of not more than a year. Our results were lower than, results of Sucilathangam.G et.al ${ }^{[24]}$ where over all $\operatorname{IgG}$ sero prevalence was $23 \%$ and of IgM was $3.8 \%$. Similarly among the control group we observed, IgG seropositivity of $11.7 \%$ and of $\operatorname{IgM}, 1.7 \%$. These results agreed with the low prevalence rate for $\operatorname{IgG}(6.7 \%)$ and $\operatorname{IgM}(1.7 \%)$ among healthy pregnant women, as reported by Amany M. Kamal etal ${ }^{[25]}$. But Borkakoty et al, from North East part of India reported high $\mathrm{IgG}$ seroprevalence (36.8\%) and IgM seroprevalence $(5.9 \%)$ in women without history of adverse pregnancy outcome. ${ }^{[26]}$ The difference in prevalence rate can be explained by variations in geographical and climatic conditions between different areas as the oocysts sporulates better in hot and humid climate.

In this study seroprevalence among $\mathrm{BOH}$ group was highest in women between 30 and 34 yrs (30\%) than younger age groups and maximum seropositive women were in second trimester ( $\mathrm{IgG}$ $20 \%$ and $\operatorname{IgM} 2 \%$ ). These results were in accordance with results of Singh et.al, where prevalence rate steadily increased from $18.1 \%$ in women of $18-25 \mathrm{yr}$ to $40.5 \%$ in women of $>40 \mathrm{yrs}$, and $\operatorname{IgM}$ seropositivity was maximum in second trimester $(2.25 \%)^{[22]}$.

No participant in our study was consuming raw/ under cooked meat in traditional home cooking. But, all were consuming raw salad. Most of the urban women were using drinking water supplied by municipality and the rural women from tube well or dug well. In the present study statistically no significant relationship was observed between the prevalence of Toxoplasma infection and risk factors like eating raw/undercooked meat and raw salad or drinking contaminated water, or contact with cats or soil, which was similar to reports of Khurana et al where there was no correlation between risk factors and seropositivity of toxoplasmosis in pregnancy ${ }^{[27]}$. But study by Chintapalli and Padmaja in south India showed a significant correlation with history of contact with pet animals $60 \%(P<0.05)$, in pregnant women ${ }^{[28]}$. Non association of risk factors with seropositivity may be explained by the fact that these risk factors play a limited role in this region due to different religious, cultural, and eating behaviour of our participants.

In our study seroprevalence in pregnant women having $\mathrm{BOH}$ from urban areas $(21.3 \%)$ were higher compared to rural areas $(15.2 \%)$.This can be explained as urban habit of eating improperly cooked poultry/mutton or contaminated junk foods and water from street vendors could be a 
source for $T$. gondii transmission. Similarly in $\mathrm{BOH}$ group, women of low socioeconomic status (34\%) had more seroprevalance than women of mid (5.7\%) and high socioeconomic status $(14.3 \%)(\mathrm{P}<.05)$ which was in accordance with seropositivity of $66.3 \%$ in low, verses $33.7 \%$ in high and mid socio-economic status $(\mathrm{P}<.05)$ as reported by Borkakoty et $\mathrm{al}^{[26}{ }^{]}$. Another observation in the same group was that women of low socioeconomic status living in urban areas, had more seroprevalance $(45.8 \%)$ than their rural counterparts $(21.7 \%)$.It seems that unhygienic poor living condition, unhealthy food habits and lack of health education regarding Toxoplasma transmission in women of low socio economic status staying in overcrowded urban slums probably favour Toxoplasma transmission.

The current study has several limitations, which must be considered before drawing any conclusion. As this is an institutional study in an urban set-up, it may not correctly represent the general population. For confirmation of acute infection in women showing both $\operatorname{IgM}$ and $\operatorname{IgG}$ seropositivity, neither ELISA could be repeated, nor IgG avidity test could be performed. Lastly pregnancy outcome of seropositive participants after anti toxoplasma therapy could not be documented. However, being the first seroprevalence study among pregnant women in this area it will help in estimating the magnitude of Toxoplasma infection and association of potential risk factors with disease, and help in patient management.

\section{Conclusion}

The current study has revealed that Toxoplasma infection during pregnancy can lead to adverse foetal out comes. Early serologic screening for primary Toxoplasma infection should be offered routinely to all pregnant women in first trimester. Pregnant woman suspected of recent infection should be confirmed at a toxoplasmosis reference laboratory, using accurate tests and correct interpretation. All women who are pregnant or planning a pregnancy should be made aware of, specific hygienic and dietary recommendations to prevent primary Toxoplasma infection.

\section{References}

1. Remington JS, McLeod R, Thulliez P \& Desmonts G.. Toxoplasmosis, infectious diseases of the fetus and newborn infant; in In Remington JS, Klein J (5th ed.). W. B. Saunders, Philadelphia, Pa. 2001;pp. 205.

2. Montoya JG \& Liesenfeld O. Toxoplasmosis. "Lancet"; 2004;363(9425): 1965.

3. G. Pappas, N. Roussos, and M. E. Falagas, "Toxoplasmosis snapshots: global status of Toxoplasma gondii seroprevalence and implications for pregnancy and congenital toxoplasmosis," International Journal for Parasitology, vol. 2009:39:1385-1394.

4. Kravetz J. D. and Federman D. G. Toxoplasmosis in pregnancy. American Journal ofMedicine 2005; 118: 212-216.

5. Kravetz J. D. and Federman D. G. Catassociated zoonoses. Archives of Internal Medicine 2002; 162: 1945-1952

6. Wong SY and Remington JS. Toxoplasmosis in pregnancy. Clinical Infectious Diseases 1994; 18: 853-861.

7. Hill D, Dubey J P Toxoplasma gondii: transmission, diagnosis and prevention. Clin Microbiol Infect. 2002; 8(10):634-40

8. Remington JS, McLeod R, Thulliez P, Desmonts G. Toxoplasmosis.In: Remington JS, Klein JO, editors. Infectious diseases in the fetus and newborn infant. 5th ed. Philadelphia : W.B Saunders Company,2001: pp. 205-346

9. Hung C-C, Fan C-K, Su K-E, Sung F-C, Chiou A-Y, Gil V, Da M Ferreira CD, Ole Carvalho JM, Cruz C, Lin Y-K, Tseng LF, Sao K-Y, Wen-Cheun Chang HSL, Shing-Hsien C. Serological screening and toxoplasmosis exposure factors among pregnant women in the Democratis Republic of Sao Tome and Principe. Trans. 
Royal Society Tropical Med. Hygiene, 2007: 101: 134-139

10. Montoya JG, Liesenfeld O. Toxoplasmosis. Lancet, 2004: 363: 1965-1976.

11. Stray-Pedersen B. Toxoplasmosis in pregnancy. Baillieres Clin Obstet Gynaecol 1993;7(1):107-37.)

12. Liesenfeld O, Press C, Montoya JG, Gill $\mathrm{R}$, Isaac-Renton JL, Hedman $\mathrm{K}$,et al. False-positive results in immunoglobulin M (IgM) toxoplasma antibody tests and importance of confirmatory testing: the Platelia Toxo IgM test. J Clin Microbiol 1997;35(1):174-8.

13. Flori P, Chene G, Varlet MN, Sung RT. Toxoplasma gondii serology in pregnant woman: characteristics and pitfalls [article in French]. Ann Biol Clin (Paris) 2009;67(2):125-33.

14. Stray-Pedersen B. Toxoplasmosis in pregnancy. Baillieres Clin Obstet Gynaecol 1993;7(1):107-37.

15. Montoya JG. Laboratory diagnosis of Toxoplasma gondii infection and toxoplasmosis. J Infect Dis 2002;185 (Suppl 1): S73-82.

16. Nash JQ, Chissel S, Jones J, Warburton F, Verlander NQ . Risk factors for Toxoplasmosis in pregnant women in Kent, United Kingdom. Epidemiol. Infect.2005; 133: 475-483

17. Song KJ, Shine JC, Shine HJ, Nam HW. eroprevalence of toxoplasmosis in Korean pregnant women. Korean J. Parasitol,2005: 43:69-71

18. Buchy P, Follezou JY, Lien TX, An TT, Tram LT, Tri DV, Cuong NM, Glaziou P, Chien BT. Serological study of toxoplasmosis in a population of drug users (Ho Chi Minh City) and pregnant women (Nha Trang). Bull. Soc. Pathol. Exot.2003; 96: 46-47.

19. Rai SK, Shibata H, Sumi K, Rai G, Rai N, Manandhar R, Gurung G,Onto K, Uga S, Matsuoka A, Shrestha HG, Matsumura
T.Toxoplasma antibody prevalence in Napalese pregnant women and women with bad obstetric history. Southeast Asian J. Trop. Med.Public Health, 1998;29: 739743.

20. Singh S, Pandit AJ. Incidence and prevalence of toxoplasmosis 2. in Indian pregnant women: a prospective study. $\mathrm{Am}$ J Reprod Immunol 2004; 52 : 276-83.

21. Akoijam BS, Shashikant, Singh S, Kapoor SK. Seroprevalence 3. of Toxoplasma infection among primigravid women attending antenatal clinic at a secondary level hospital in North India. J Indian Med Assoc 2002; 100 : 591-2, 594-6, 602.

22. Singh S, Munawwar A, Rao S, Mehta S, Hazarika NK (2014) Serologic Prevalence of Toxoplasma gondii in Indian Women of Child Bearing Age and Effects of Social and Environmental Factors. PLoS Negl Trop Dis.2014; 8(3): e2737.

23. Anubhuti, Radha Rani Roy, J. P. Mittra, Shoukat Jahan Begum : Seroprevalence of Toxoplasma Gondii in Spontaneous Abortions in Pregnant Women. Journal of Evolution of Medical and Dental Sciences 2015; 39; 6763-6768.

24. Sucilathangam G, Anna T, Velvizhi G: Seroprevalence of Toxoplasma Gondii in Pregnant Women with Bad Obstetric History,Indian Journal of Research 2013;11:240-242

25. Amany M. Kamal1, Azza K. Ahmed1,*, Manal Z. M. Abdellatif1, Mohamed Tawfik2, Ebtesam E. Hassan3 Seropositivity of Toxoplasmosis in Pregnant Women by ELISA at Minia University Hospital, Egypt . Korean J Parasitol 2015 Vol ; 53: 605-610

26. Borkakoty BJ, Borthakur AK, Gohain M. Prevalence of Toxoplasma gondii infection amongst pregnant women in Assam, India. Indian J Med Microbiol 2007; 25:431-2.

27. Khurana S, Bagga R, Aggarwal A, Lyngdoh V, Shivapriya, Diddi K, et al. 
Serological screening for antenatal toxoplasma infection in India. Indian $\mathbf{J}$ Med Microbiol 2010;28:143-6.

28. Chintapalli S, Padmaja IJ. Seroprevalence of toxoplasmosis in antenatal women with bad obstetric history. Trop Parasitol 2013;3:62-6 